\title{
Postextinction Infusion of a Mitogen-Activated Protein Kinase Inhibitor Into the Medial Prefrontal Cortex Impairs Memory of the Extinction of Conditioned Fear
}

\author{
Sandrine Hugues, Olivier Deschaux, and René Garcia ${ }^{1}$ \\ Neurobiologie Comportementale, JE Neurobiologie \& Psychopathologie, Université de Nice-Sophia Antipolis, 06108 Nice, France
}

\begin{abstract}
We investigated whether postextinction training infusion of PD098059, a selective inhibitor of mitogen-activated protein kinase (MAPK) activation, into the medial prefrontal cortex, would impair retention of extinction learning in rats. We found that immediate, but not late ( 2 or 4 h), postextinction infusion of PD098059 provoked a full return of conditioned freezing. These results suggest that activation of prefrontal MAPK in early stages of postextinction training participates in processes that protect against spontaneous recovery of aversive responses.
\end{abstract}

Conditioned responses are known to extinguish following repetitive presentations of the conditioned stimulus (CS) without the unconditioned stimulus (US). However, with the passage of time, further reexposure to the CS alone can reactivate these extinguished responses, a phenomenon termed spontaneous recovery (Pavlov 1927). This phenomenon seems to depend, at least for fear conditioning, on the postextinction direction of changes in synaptic efficacy in the medial prefrontal cortex (mPFC). Indeed, both human (Fernandez et al. 2001) and animal (Herry and Garcia 2002, 2003; Milad and Quirk 2002) studies have revealed that extinction of conditioned traumatic responses can be characterized by an increase, a decrease, or no changes in neuronal activity in the mPFC. Most important, follow-up tests carried out at both short ( $24 \mathrm{~h}$ ) and long (7 d) postextinction delays have shown that when extinction was accompanied by a potentiation of $\mathrm{mPFC}$ neuronal activity, it was not followed by a spontaneous recovery of extinguished responses (Herry and Garcia 2002; Milad and Quirk 2002). In contrast, when it was accompanied by a depression of mPFC synaptic efficacy (Herry and Garcia 2002, 2003) or a lack of changes in prefrontal neuronal activity (Milad and Quirk 2002), extinction was always found to be followed by a full recovery of conditioned fear responses.

Here we tested whether a blockade of mitogen-activated protein kinase (MAPK) activation, which is involved in activitydependent modulation of synaptic strength in various brain areas (e.g., English and Sweatt 1997; Coogan et al. 1999; Huang et al. 2000), including the mPFC (Otani et al. 1999), would interfere with the long-term maintenance of extinction of conditioned fear responses. We used PD098059 as a selective inhibitor of MAPK activation with a single dose $(1 \mu \mathrm{L} /$ side $)$ known to interfere with the formation of long-term cognitive memory, as shown when infused in the hippocampus (Blum et al. 1999). Placements of the cannulae, verified by standard histological methods, were found to be correct (Fig. 1) in all injected rats.

During the first session of five tone-alone presentations, shocked rats exhibited high levels of freezing both before and during the explicit CS presentation (Fig. 2A,B). This conditioned fear response significantly decreased from the first to the third

'Corresponding author.

E-MAIL rene.garcia@unice.fr; FAX 33-4-9207-6162.

Article and publication are at http://www.learnmem.org/cgi/doi/10.1101/ Im.77704. session (during PreCS: $F_{(2,32)}=3.76, P<0.05$; during CS: $\left.F_{(2,32)}=14,58, P<0.0001\right)$. Nonshocked rats displayed low levels of freezing during the three sessions. A two-factor repeated measures ANOVA on these data showed a significant main effect of group (PreCS: $F_{(1,36)}=9.09, P<0.005$; during CS: $F_{(1,36)}=18.65$, $P=0.0001$ ), without any effect of session (in both cases, $F<1$ ). This absence of effect of session resulted from the increase in freezing exhibited by nonshocked rats from the first to third session. This increase in freezing was probably a result of our paradigm (three sessions of exposure to both contextual and explicit cues with a 1-h interval), which produced habituation characterized by a decreased exploratory behavior (i.e., an increase in freezing behavior). However, the Group $\times$ Session interaction was significant (PreCS: $F_{(2,72)}=3.24, P<0.05$; during CS: $\left.F_{(2,72)}=5.87, P<0.005\right)$.

During the fourth session of five tone-alone presentations, noninjected shocked rats exhibited very low levels of freezing that did not differ from the nonshocked animals, revealing that the three previous sessions were sufficient to completely extinguish the conditioned freezing. Similarly, re-exposure of shocked rats, injected with vehicle, to both contextual and explicit cues did not induce any conditioned freezing response whatever the time point of injection (Fig. 2C,D). Statistical analyses confirmed that each of these three groups did not differ from the nonshocked animals (all $P>0.05$ ), indicating a full maintenance of extinction. However, rats that immediately received PD098059 infusion into the mPFC after the extinction training fully recovered their conditioned freezing to both contextual and explicit cues, which did not statistically differ from levels of freezing observed during the first session of extinction training but did significantly differ from levels of freezing observed in rats that received vehicle at the same delay (both before and during CS: $P<0.05$ ) and noninjected subjects (nonshocked and shocked: all $P<0.05)$. Rats injected with PD098059 at a 2 -h postextinction delay displayed higher but nonsignificant levels of freezing to the explicit cues when compared both with rats that received vehicle at the same delay and with noninjected subjects (all $P>0.05$ ). Infusion of PD098059 at a 4-h postextinction delay did not affect expression of extinction memory in the presence of both contextual and explicit cues (Fig. 2C,D). This was confirmed by statistical analyses showing that these rats $(4 \mathrm{~h})$ did not differ from subjects that received vehicle at the same postextinction delay, or 
A

\begin{tabular}{ccc} 
D1-D3 & D4 & D5 \\
\hline $\boldsymbol{\nabla}$ & \multicolumn{1}{|c}{} & $\mathbf{V}$ \\
Acclimation & $\begin{array}{c}\text { Conditioning } \\
\text { - CTXA - }\end{array}$ & Extinc \\
(15 min/day) & (5 CS B - US $)$ & - CTX \\
(3)
\end{tabular}

B

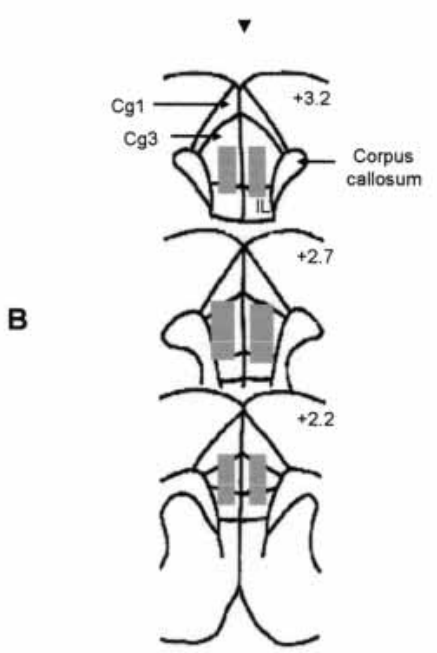

Figure $1(A)$ Experimental timeline. Acclimation took place in one context (CTX A), whereas conditioning and extinction took place in a different context (CTX B). (B) Areas of cannulae tip locations in the mPFC (gray areas). Cg1 and Cg3: cingulate areas 1 and 3; IL: infralimbic area.

from both noninjected nonshocked and shocked (all $P>0.05$ ). This finding indicates that delayed injection of an inhibitor of MAPK spares mPFC functioning required for synaptic plasticity changes associated with the long-term retention of extinction memory.

Our data show that postextinction inhibition of MAPK activation in the MPFC, via bilateral infusion of PD098059, impairs memory of extinction of conditioned freezing as a function of postextinction delay with the highest effects immediately after extinction and no effect at $4 \mathrm{~h}$. Taking into account the role of postextinction potentiation of prefrontal synaptic efficacy in the protection against spontaneous recovery, these data suggest that immediate postextinction MAPK activity crucially mediates the induction and probably the maintenance, via its downstream effects, of postextinction synaptic plasticity changes in the mPFC.

Furthermore, because changes in neuronal activity in the medial prefrontal cortex developed only after several presentations of CS-alone whatever the protocol used (massed or spaced protocol; Herry and Garcia 2002, 2003, respectively), we suggest that neurochemical changes within the mPFC may also take place as a consequence of repeated CS-alone presentations even with spaced protocol with a 1-h interval between sessions (the present study).

Although this study was not combined with electrophysiological analyses of prefrontal synaptic plasticity, the link between the recovery of extinguished conditioned freezing and blockade of postextinction potentiation of synaptic efficacy in the mPFC is largely supported by previous findings. First, the absence of spontaneous recovery has been reported to be associated with postextinction potentiation of prefrontal neuronal activity (Herry and Garcia 2002; Milad and Quirk 2002). For example, in previous studies, analyzing prefrontal field potentials, potentiation of synaptic efficacy did not develop during the first session of CS-alone presentations but were fully expressed during the period that followed this session (Herry et al. 1999; Herry and Garcia 2002). In addition, all animals displaying these changes did not exhibit a fear return when reexposed to the CS (tone).
Second, lesion studies have shown that suppression of such possibilities of prefrontal synaptic plasticity (i.e., absence of postextinction potentiation resulting from tissue damage in the $\mathrm{mPFC}$ ) is associated with the recovery of extinguished fear responses (Quirk et al. 2000). Furthermore, electrophysiological studies also indicated that the return of prefrontal synaptic efficacy to baseline levels during the first extinction session was a prerequired condition to the development of postextinction potentiation of synaptic efficacy in the mPFC (Herry et al. 1999; Herry and Garcia 2002). Remarkably, blockade of this return to the baseline values by application of thalamic low-frequency stimulation (Herry and Garcia 2002), or its behavioral disruption (Herry and Garcia 2003), during the extinction training was found to be associated with a full return of conditioned freezing during follow-up tests. From these electrophysiological findings, one can suggest that all rats in the present studies developed such changes (from depression to baseline restoration of prefrontal synaptic efficacy) during extinction training. However, infusion of PD098059 into the mPFC immediately after the extinction training interrupted processes necessary to the development of potentiation of synaptic efficacy in the mPFC. This was, therefore, characterized during follow-up tests by a return of extinguished conditioned responses, whereas the other rats (which were conditioned and subjected to extinction training, but that did not receive PD098059) were protected against this return of fear responses because of a normal development of prefrontal postextinction potentiation in these animals.

Bilateral infusion of PD098059 into the basolateral amygdala (probably affecting the surrounding areas) has also been reported to interfere with extinction of conditioned fear responses (Lu et al. 2001). Because the mPFC and the amygdala reciprocally modulate their neuronal activity during emotional processes (Garcia et al. 1999; Quirk et al. 2003; Roozendaal et al. 2004), it is possible that interactions, mediated in part by MAPK activation, between the two structures during extinction learning may contribute the formation of long-term memory of extinction.

The MAPK inhibitor used here, PD098059, had also been previously found to alter formation of other types of long-term memory formation. For example, posttraining infusion of this compound into the entorhinal cortex produced a spatial memory deficit during the retention test (Hebert and Dash 2002). Likewise, intraventricular injection of the same compound impaired long-term memory for contextual and auditory fear (Schafe et al. 1999).

Together with the present data, one can conclude that MAPK activity is involved in multiple types of long-term memory formation, including, in fear conditioning domain, trace fear conditioning (Runyan et al. 2004). However, further studies are needed to determine the specific family of MAPK that is transiently activated in the mPFC immediately following extinction training.

In this study, subjects were adult male Wistar rats (250-350 g), individually caged (Plexiglas cages) with unlimited access to food and water, and maintained on a 12-h light/12-h dark cycle 


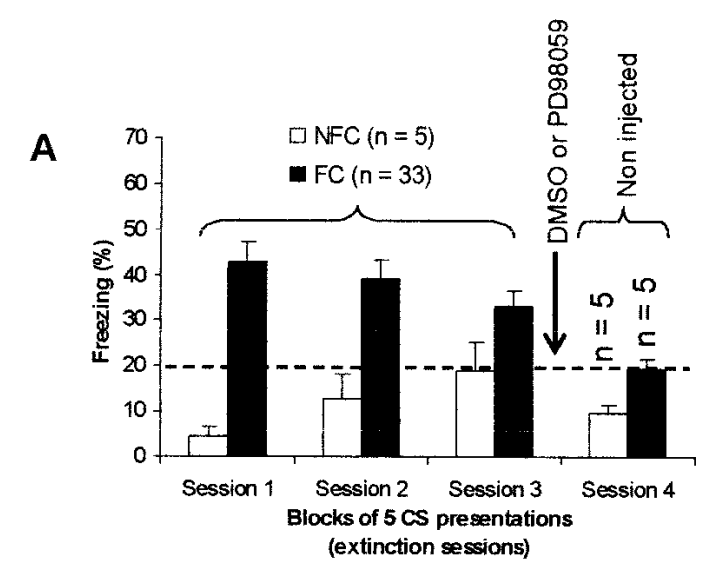

B

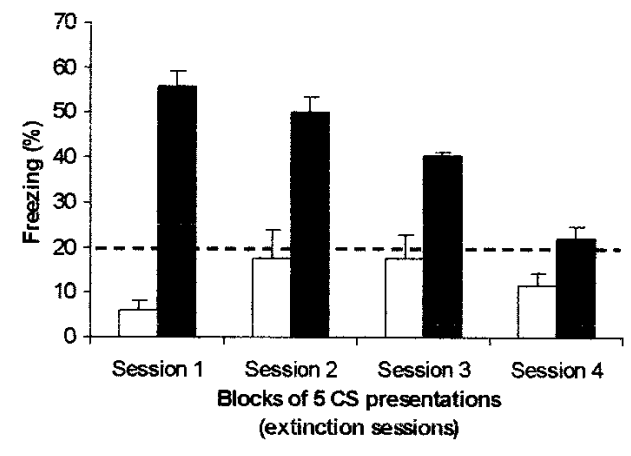

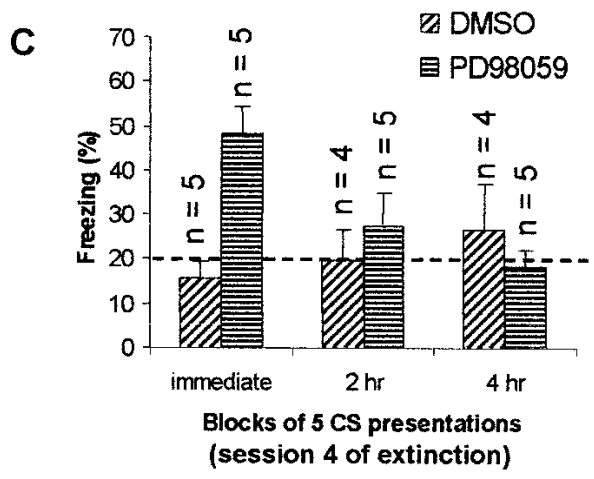

D

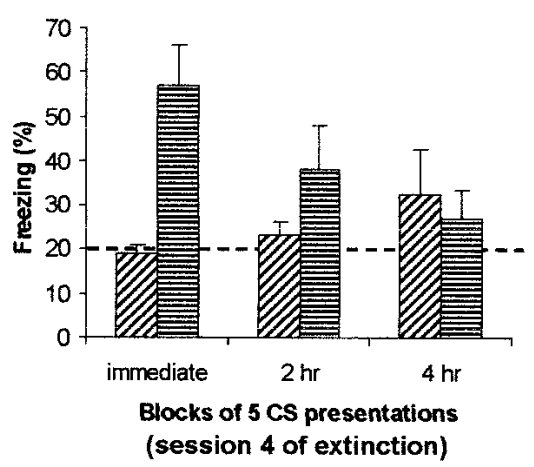

Figure 2 Mean percentage of freezing behavior ( \pm SEM) scored during the four sessions of extinction. $(A, C)$ Freezing to the context (i.e., during the $30 \mathrm{sec}$ preceding each tone presentation); $(B, D)$ Freezing to the explicit cue (i.e., during the 30 -sec period of tone presentation). Sessions $1-3$ were separated by a 1 -h period, whereas sessions 3 and 4 were separated by $10 \mathrm{~d}$, with injection of the vehicle (DMSO) or PD98059 taking place after session 3 at different delays (immediately, $2 \mathrm{~h}$, or $4 \mathrm{~h}$ later). Before injection, all conditioned animals (FC) were submitted to the same regimen. These data are consequently pooled (sessions $1-3 ; n=33$ ). However, in session 4 of extinction, data from FC animals are presented as a function of the type of injection or the absence of injection (noninjected animals). Dotted lines correspond to the highest levels of freezing observed with nonshocked animals (NFC).

(lights on at 8:00 a.m.). They were anesthetized with sodium pentobarbital (65 $\mathrm{mg} / \mathrm{kg}$, intraperitoneally) and were bilaterally implanted with 30-gauge guide cannulae aimed $1 \mathrm{~mm}$ above the mPFC infralimbic area $(3.2 \mathrm{~mm}$ anterior to bregma, $0.6 \mathrm{~mm}$ lateral to midline, and $4 \mathrm{~mm}$ from cortical surface). In addition to this cannula placement, two stimulating electrodes (silver wires, diameter $110 \mu \mathrm{m}$, insulated except at the tip, 0.4-0.6 mm exposed) were inserted in the right eyelid for shock administration. The entire miniature system was fixed in place onto the skull with dental cement. Subjects were then allowed to recover in their home cages in the animal room for at least $4 \mathrm{~d}$.

Following recovery from surgery, rats were exposed to a first box (box A, with four vertical sides, each $30 \mathrm{~cm}$ wide) for $15 \mathrm{~min}$. The fourth day, they were placed into a second box (box B, with six vertical sides, one $30 \mathrm{~cm}$, three $25 \mathrm{~cm}$, and two $10 \mathrm{~cm}$ wide), where fear conditioning and extinction took place. Each box was placed inside a sound-attenuating and temperature-regulated chamber (Imetronic, Pessac). A speaker was placed at the top of the chamber to provide a $30-\mathrm{sec} / 2.5-\mathrm{kHz} / 75-\mathrm{dB}$ tone (CS). A spiral cable from a rotating connector, at the top of the chamber, was connected to the animal headstage to deliver to the eyelid the shock (US), which consisted of a train of eight pulses $(5 \mathrm{~Hz} /$ $3.5 \mathrm{~mA}$ ), from a stimulator (Master-8). A microcomputer program (Imetronic Software), piloted from an adjacent room (observatory control room), controlled stimulus delivery (tone-eyelid shock or tone-alone presentations). The behavior of each animal was continuously monitored and, when necessary, recorded via a
camera-VCR-monitor system from the observatory-control room. The floor, of rough plastic, and the four walls of box A were washed with a solution containing a mixture of coconut and vanilla scent before introducing the animal. Box B, with a smooth plastic floor, was washed with a solution containing a mixture of ethanol (50\%) and lemon scent.

In box $\mathrm{B}$, on the fourth day, rats were exposed to five tone presentations (interstimulus interval: $30-120 \mathrm{sec}$ ); each was followed by an eyelid shock administration (shocked group; $n=33$ ), except for five animals that served as controls (nonshocked group). After these stimulus presentations, all animals were returned to their home cages in the animal room for $24 \mathrm{~h}$. After this delay, the tone presentation schedule was repeated three times in context A without any eyelid shock administration (sessions 1, 2, and 3 of extinction), with a 1-h interval during which animals were left undisturbed in their home cages in the animal room. Following the third session of extinction, all of the shocked rats, except for five, was injected either immediately or 2 or $4 \mathrm{~h}$ later with either PD098059 or vehicle (DMSO-saline) into the mPFC. The tip of the infusion cannula protruded $1 \mathrm{~mm}$ beyond the guide cannula and was aimed at the MPFC infralimbic area. Through the infusion cannula, animals received bilateral $1-\mu \mathrm{L}$ infusions of vehicle (made of 50\% dimethyl sulfoxide [DMSO] and 50\% saline) or PD098059 (made of 10\% PD098059 at $2 \mathrm{mg} /$ $\mathrm{mL}, 40 \% \mathrm{DMSO}$, and $50 \%$ saline) over a 2 -min period. An additional 1-min period was allowed for diffusion of the drug. The 10 noninjected rats (five shocked and five nonshocked animals) 
were handled as for immediate drug infusion, but without any injection. All animals were re-exposed to both contextual cues and tone (one session of five CS-alone presentations; interstimulus interval: $30-120 \mathrm{sec}$ ) $10 \mathrm{~d}$ later (fourth session).

Freezing behavior was measured during the 30 -sec period preceding each discrete CS presentation (freezing to contextual cues) and during the 30 -sec period of each tone presentation, using a time-sampling procedure. A rat was considered to freeze when it adopted a motionless posture, refraining from all but respiratory movements (Blanchard and Blanchard 1968).

\section{ACKNOWLEDGMENTS}

This study was supported by the INSERM-Programme Avenir (R.G.) and a grant from the Délégation Générale pour l'Armement to S.H.

\section{REFERENCES}

Blanchard, R.J., and Blanchard, C. 1968. Crouching as an index of fear. J. Comp. Physiol. Psychol. 6: 370-375.

Blum, S., Moore, A.N., Adams, F., and Dash, P.K. 1999. A mitogen-activated protein kinase cascade in the CA1/CA2 dsubfield of the dorsal hippocampus is essential for long-term spatial memory. J. Neurosci. 19: 3535-3544.

Coogan, A.N., O'Leary, D.M., and O'Connor, J.J. 1999. P42/44 MAP Kinase inhibitor PD98059 attenuates multiple forms of synaptic plasticity in rat dentate gyrus in vitro. J. Neurophysiol. 81: 103-110.

English, J.D. and Sweatt, J.D. 1997. A requirement for the mitogen-activated protein kinase cascade in hippocampal long-term potentiation. J. Biol. Chem. 272: 19103-19106.

Fernandez, M., Pissiota, A., Frans, O., von Knorring, L., Fischer, H., and Fredrikson, M. 2001. Brain function in a patient with torture related post-traumatic stress disorder before and after fluoxetine treatment: a positron emission tomography provocation study. Neurosci. Lett. 297: 101-104.

Garcia, R., Vouimba, R.M., Baudry, M., and Thompson, R.F. 1999. The amygdala modulates prefrontal cortex activity relative to conditioned fear. Nature 402: 294-296.

Hebert, A.E. and Dash, P.K. 2002. Extracellular signal-regulated kinase activity in the entorhinal cortex is necessary for long-term spatial memory. Learn. Mem. 9: 156-166.
Herry, C. and Garcia, R. 2002. Prefrontal cortex long-term potentiation, but not long-term depression, is associated with the maintenance of extinction of learned fear in mice. J. Neurosci. 22: 577-583.

. 2003. Behavioral and paired-pulse facilitation analyses of long-lasting depression at excitatory synapses in the medial prefrontal cortex in mice. Behav. Brain Res. 146: 89-96.

Herry, C., Vouimba, R.M., and Garcia, R. 1999. Plasticity in the mediodorsal thalamo-prefrontal cortical transmission in behaving mice. J. Neurophysiol. 82: 2827-2832.

Huang, Y.Y., Martin, K.C., and Kandel, E.R. 2000. Both protein kinase A and mitogen-activated protein kinase are required in the amygdala for the macromolecular synthesis-dependent late phase of long-term potentiation. J. Neurosci. 20: 6317-6325.

Lu, K.T., Walker, D.L., and Davis, M. 2001. Mitogen-activated protein kinase cascade in the basolateral nucleus of amygdala is involved in extinction of fear-potentiated startle. J. Neurosci. 21: RC162.

Milad, M.R. and Quirk, G.J. 2002. Neurons in medial prefrontal cortex signal memory for fear extinction. Nature 420: 70-74.

Otani, S., Auclair, N., Desce, J.M., Roisin, M.P., and Crepel, F. 1999. Dopamine receptors and groups I and II mGluRs cooperate for long-term depression induction in rat prefrontal cortex through converging postsynaptic activation of MAP kinases. J. Neurosci. 19: 9788-9802.

Pavlov, I.P. 1927. Conditioned Reflexes. Oxford University Press, Oxford, UK.

Quirk, G.J., Russo, G.K., Barron, J.L., and Lebron, K. 2000. The role of ventromedial prefrontal cortex in the recovery of extinguished fear. J. Neurosci. 20: 6225-6231.

Quirk, G.J., Likhtik, E., Pelletier, J.G., and Pare, D. 2003. Stimulation of medial prefrontal cortex decreases the responsiveness of central amygdala output neurons. J. Neurosci. 23: 8800-8807.

Roozendaal, B., McReynolds, J.R., and McGaugh, J.L. 2004. The basolateral amygdala interacts with the medial prefrontal cortex in regulating glucocorticoid effects on working memory impairment. $J$. Neurosci. 24: 1385-1392.

Runyan, J.D., Moore, A.N., Dash, P.K. 2004. A role for prefrontal cortex in memory storage for trace fear conditioning. J. Neurosci. 24: 1288-1295.

Schafe, G.E., Nadel, N.V., Sullivan, G.M., Harris, A., and LeDoux, J.E. 1999. Memory consolidation for contextual and auditory fear conditioning is dependent on protein synthesis, PKA, and MAP kinase. Learn. Mem. 6: 97-110.

Received March 30, 2004; accepted in revised form July 8, 2004. 


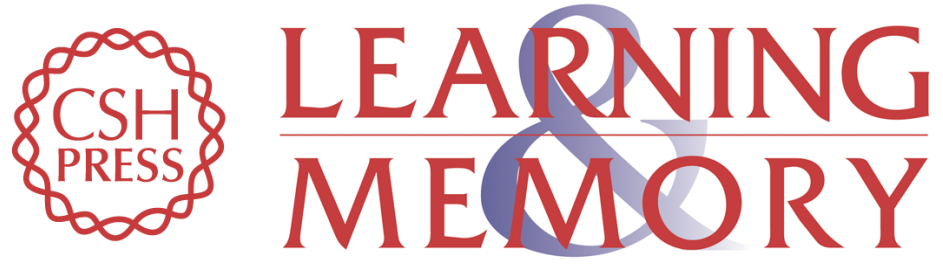

\section{Postextinction Infusion of a Mitogen-Activated Protein Kinase Inhibitor Into the Medial Prefrontal Cortex Impairs Memory of the Extinction of Conditioned Fear}

Sandrine Hugues, Olivier Deschaux and René Garcia

Learn. Mem. 2004, 11:

Access the most recent version at doi:10.1101//m.77704

References This article cites 18 articles, 12 of which can be accessed free at: http://learnmem.cshlp.org/content/11/5/540.full.html\#ref-list-1

License

Email Alerting

Receive free email alerts when new articles cite this article - sign up in the box at the Service top right corner of the article or click here. 